$$
\begin{array}{r}
\text { UN SUEÑO BLAN } \\
\text { REFLEXIONES SOB } \\
\text { EDUCACIÓN MBYA-GUA } \\
\text { EN ARGEN }
\end{array}
$$




\section{UN SUEÑO BLANCO: REFLEXIONES SOBRE LA EDUCACIÓN MBYÁ-GUARANI EN ARGENTINA}

\section{N O E L I E N R I Z}




\section{Resumen}

\section{UN SUEÑO BLANCO: REFLEXIONES SOBRE LA EDUCACIÓN MBYÁ-GUARANI EN ARGENTINA}

La población indígena de Misiones (Argentina), en su mayoría Mbyá-Guaraní, ha estado en el foco de las diferentes políticas públicas desde la década de 1970. En este trabajo, proponemos que se consideren las características, los conceptos teóricos y objetivos de las políticas de esta primera intervención. Luego de considerar las consecuencias actuales de esa intervención, especialmente en lo que respecta a la escolarización, teniendo en cuenta algunas relaciones entre este modelo de intervención y las actuales políticas educativas. Palabras clave: Mbyá-Guarani, políticas públicas, Antropología aplicada.

\section{Abstract \\ A WHITE DREAM: SOME THOUGHTS ON MBYÁ-GUARANI EDUCATION IN ARGENTINA}

The indigenous population of Misiones (Argentina), mostly Mbyá-Guarani, has been in the focus of different public policies from the 1970s. In this paper, we propose to consider the characteristics, theoretical concepts and objectives of these first policies of intervention. Then, the ongoing consequences of that intervention are considered, especially with regard to schooling, taking into account some relations between this model of intervention and current educational policies.

Keywords: Mbyá-Guarani, public policies, applied Anthropology.

\section{Resumo}

\section{UM SONHO BRANCO: REFLEXÕES SOBRE A EDUCAÇÃO MBYÀ-GUARANI NA ARGENTINA}

A população indígena de Misiones (Argentina), na maior parte Mbyá-Guarani, foi foco das diferentes políticas públicas a partir da década de 1970. Neste trabalho, propomos a considerar as características, os conceitos teóricos e os objetivos destas primeiras políticas de intervenção. Então vamos considerar as conseqüências da intervenção em curso, especialmente no que diz respeito à escolaridade, tendo em conta algumas relações entre este modelo de intervenção e as atuais políticas educativas.

Palavras-chave: Mbyá-Guarani, políticas públicas, Antropología aplicada. 


\section{INTRODUCCIÓN}

'Le pidieron que hable, una religiosa le pidió que hable, a él no le costaba hablar en público. Se puso de pié y caminando en un recorrido pequeño por el salón, de espaldas a las pantallas de proyección y las pizarras explicó cuanto le interesaba participar de la escuela, pero aclaró que la escuela era un sueño blanco - lo dijo en perfecto castellano" (Registro de campo, Posadas, Octubre 2006).

Utilizamos esa frase como metáfora de lo que pueden significar las intervenciones de las ciencias sociales en los grupos. En tiempos en que la antropología es llamada a aportar en la consolidación de grupos que se ocupen de programas sociales en diversas áreas - tanto en lo educativo ${ }^{1}$, como en planes de viviendas, por citar solo algunos ejemplos -, consideramos necesaria la reflexión sobre las dinámicas de intervención desarrolladas, sus características y las concepciones teóricas que sustentaron estas acciones.

Utilizamos la frase destacada del primer párrafo, también como metáfora particular. Por un lado, porque fue expresada por un auxiliar bilingüe ${ }^{2}$, en el marco de un encuentro organizado por el Ministerio de Educación de la Provincia de Misiones de "Relatos de Experiencias". Además, porque el auxiliar se encuentra estrechamente ligado a la instancia de intervención que anclará este texto: "Proyecto de desarrollo integral de las comunidades guaraníes de Fracrán y Peruti". Finalmente la utilizamos, porque después de 25 años de asientos y pupitres, fue dicha en medio de una reflexión que comenzó en lengua mbyá, de pie y caminando, es decir, del modo en que los mbyá dicen las cosas más relevantes.

En este trabajo nos proponemos establecer relaciones entre las dinámicas poblacionales y las políticas públicas. Tomaremos el caso particular de la relación entre la antropología y las políticas para población indígena, en torno a al población Mbyá guaraní que habita en la provincia de Misiones (Argentina). Analizaremos las características del "Proyecto de Desarrollo Integral", sus efectos y las concepciones teóricas que dieron lugar a su emplazamiento. Por último, revisaremos críticamente, a partir de las experiencias de campo ${ }^{3}$, las marcas actuales de la existencia de estas políticas.

\section{ALGUNOS ELEMENTOS DE CON- TEXTUALIZACIÓN}

Los mbyá que habitan en la provincia de Misiones entraron recientemente al proceso de sedentarización - podríamos aventurar que en los últimos 50 años -, e incluso utilizan diversas estrategias que permiten pensar que la movilidad permanece vigente. Estas condiciones pueden haber dado lugar a pensar escenarios muy contradictorios; ya que mientras en los medios masivos de comunicación de la provincia de misiones se expresaba como frágil su existencia ${ }^{4}$, los desarrollos teóricos consideraran su expansión y permanencia (ver Susnik 1983, Cadogan 1971, 1948, 1997).

Los mbyá son una parcialidad guaraní que, durante la primera conquista reli- 
giosa, fue considerada montaraz y que, en ese contexto de desplazamiento hacia el interior de la Selva Paranaense, mantuvieron su propia variedad lingǘstica, la subsistencia cazadora recolectora y la propia religiosidad. El territorio que los guaraní habitaron ancestralmente ha sido atravesado por diversas fronteras nacionales (Paraguay, norte de Argentina y sur de Brasil). La movilidad a través de esas fronteras le ha dado una característica muy particular al desarrollo de esta población en lo linguístico - por su vinculación con el español, otras formas del guaraní y el portugués - , en lo político - por la relación con tres estados nacionales diferentes $-\mathrm{y}$ también en las relaciones con la población criolla de cada región - en todos los casos acogedora de europeos.

Garlet y Assis (2009) sostienen que la tensión entre desterritorialización y reterritorialización ha sido la calve de circulación Mbyá, destinados a habitar el monte, pero obligados por las presiones - del 'contacto interétnico' - sobre el territorio a alojarse en también otras zonas. En el caso misionero estas migraciones dieron lugar a la visibilización de la población y el diseño de políticas específicas, aunque no han dado origen a sentamientos urbanos ni periurbanos, como en otras regiones.

Por otro lado, el interés de las políticas del Estado provincial por la población indígena comenzó en la década del setenta, sólo antecedido por algunos intentos censales, en 1966 (producto del decreto nacional 3998/65). Si bien las políticas públicas comenzaron tardíamente, lo hicieron con mucho vigor.
El "Programa de Desarrollo Integral" fue la primera propuesta de intervención a nivel local. Se elaboró en 1978 para ser ejecutado durante 10 años y abarcaba una serie de subprogramas. El mismo fue impulsado por el Instituto Superior Antonio Ruiz de Montoya (ISPARM), con amplio apoyo del gobierno de turno. El 13 de junio de 1981 se inauguró en Peruti ${ }^{5}$, el núcleo donde pondremos el eje de nuestra mirada e inspirador de esta indagación, la estructura edilicia y sus chacras (el 20 de junio de 1983 lo haría Fracrán). Dadas las condiciones políticas de la época, la información de gobierno ha sido poco transparente, incluso los mayores centros de documentación del país han sido privados de conservar materiales, fundamentalmente de prensa, tal es el caso de la Biblioteca del Congreso de la Nación, por citar uno. Sirva este comentario de reserva respecto de las fuentes encontradas en el Archivo de la Provincia de Misiones, no sólo escasas, sino fragmentarias e inconexas. Peruti se ubica en el centro oeste de la provincia de Misiones, municipio de Libertador General San Martín, próximo a la localidad de El Alcazar 6 .

Esta política de intervención se diseñó conjuntamente entre miembros del estado provincial y miembros de la jerarquía eclesiástica local. La política educativa, sobre la que focalizaremos en este texto, ha sido la más influida por esta relación, ya que la escolarización se diseñó desde propuestas de institutos religiosos. Pero lo más relevante es que son instituciones que incluso en la actualidad son de subvención estatal, 
pero de gestión privada, a través del Obispado ${ }^{7}$. Los subprogramas que se desarrollaron eran los siguientes: Vivienda, Higiene y Casa de la Salud para la vida sedentaria, Nutrición infantil y del Adulto, Trabajo agrícola y ganadero (aves y cerdos), Economía familiar y comunitaria, Agua potable y energía, Educación bilingüe y escuela de doble escolaridad, Comedor escolar y huerta comunitaria, Alfabetización de los adultos, Formación laboral de la mujer (costura, cocina, panadería, peluquería), Cooperativa de consumo y cooperativa artesanal, Casa de la cultura y relación social con la comunidad circundante, Talleres de máquinas y carpintería.

Así fue que se establecieron viviendas de material para las familias, una carpintería (con un gran tinglado, maquinaria y profesionales que aportaban el conocimiento para la explotación), un criadero de pollos y cerdos (con herramientas para faena) y una panadería (igualmente instalada), a lo que se sumó una escuela doble turno con comedor escolar perteneciente a la gestión privada, vinculada al Obispado, un taller de costura par las mujeres, las viviendas necesarias para representantes eclesiásticos y docentes.

Estos programas se proponían "posibilitar la paulatina integración de los aborígenes en el proceso de desarrollo provincial favoreciendo la participación de los mismos" (Acción de gobierno 1976-1983). Se proponían facilitar la inclusión en el mercado y la formación para esta participación.

En este texto analizaremos la relación entre las políticas públicas y las ciencias sociales, en torno a la idea de investigación acción. Consideramos que las políticas se diseñaron sin considerar el impacto de las mismas, y que en ellas se ha reflejado desconocimiento de la población indígena. Estos dos elementos dieron como resultado el fracaso de ciertos aspectos materiales de las políticas. Entre los elementos que se han mantenido, se destaca la escuela. Reflexionaremos sobre las percepciones de los auxiliares bilingües, respecto de esta institución.

\section{LAS CIENCIAS SOCIALES Y LA INTER- VENCIÓN}

Pensar a las ciencias sociales como tales supone el interés por las personas, por los procesos sociales, por las condiciones de los mismos. Este interés ha sido fogueado por las dinámicas de los estados. El consabido impulso de la antropología en sus inicios por las dinámicas de expansión colonial no hace más que confirmar esto. Así, podríamos decir, que las ciencias sociales, y la antropología particularmente, han debatido con las políticas públicas. La expansión de los estados no podía más que augurar ordenamiento y control. Como afirmara tempranamente Comte, las exigencias de la práctica se hallan insertas en el origen de la ciencia.

En el proceso de legitimación de la antropología como ciencia, no solo estaba en juego su objeto de estudio y su metodología, sino también su posible aplicabilidad. De algún modo estos intereses motivaban a los gobiernos coloniales en sus políticas. Si bien han 
sido varios los antropólogos que formaron parte de esos primeros pasos de la disciplina, Malinowski (1991: 13-14) expresa claramente esta tensión en una de sus primeras obras, "la antropología es todavía para la mayoría de los profanos y para muchos especialistas un objeto de interés anticuario. (...) Sin embargo hay ciertos aspectos de la antropología que tienen un carácter científico autentico en el sentido de que (...) ensanchan nuestro conocimiento de la naturaleza humana y pueden llevarnos a una aplicación práctica directa. Me refiero por ejemplo a una materia como la economía primitiva" otro ejemplos que propone son el estudio de los procesos mentales y, por supuesto, la ley primitiva, de que el mismo se ocuparía.

"La revolución científica introducida por la obra de Malinowski (...) responde en último análisis a la lógica de la colonización" (Bastide 1977: 23). Contrariamente al planteo relativista, "si se puede hablar del dilema de la antropología cultural es porque su relativismo nunca llega hasta sus consecuencia lógica, y mantiene en lo íntimo ese etnocentrismo que, sin embargo, denuncia en las concepciones ajenas" (op. cit.: $20)$. Bastide propone que la antropología cultural siempre concedió gran valor en sus investigaciones a "los fenómenos de aculturación, es decir, a la difusión en transe de concretarse", en referencia a los estudios de Boas y sus herederos.

Estas prácticas disciplinares, incluso después de que la antropología se replanteara su relación con las políticas colonizadoras, mantienen focos de discusión. En su relato sobre la antropo- logía argentina Pablo Perazzi reconstruye algunos procesos vinculados a la producción de políticas públicas. Las mismas habrían dado sus primeros pasos durante el gobierno peronista, en el seno del Instituto Étnico Nacional, creado en 1946; su objetivo era "emprender estudios que echaran luz sobre la situación demográfica nacional y permitieran planificar actividades económicas" (Perazzi 2003: 59-60).

Las experiencias de intervención de que se nutre este análisis, se consideran herederas de Roger Bastide. En el caso de Misiones, antropólogos formados en esta corriente se encargaron particularmente del diseño de estas políticas, mientras ocupaban cargos ministeriales. En el caso específico de la cuestión escolar, las propuestas se impulsaron a través de instituciones de formación docente dependientes del Obispado local ${ }^{8}$.

Por otro lado, frente al desconocimiento y la espasmódica intervención en relación con la población indígena, la explotación del territorio se habría desarrollado a partir de la idea de despoblamiento. Así, las políticas de poblamiento se dirigieron a población extranjera y campesina. La Ley $\mathrm{Na}$ cional de Colonización (1876) y la Ley de Ventas de Tierras Fiscales (1882) aceleraron el proceso de ocupación de territorios. A partir de 1890, la provincia se puebla de colonos provenientes de distintas zonas de Europa, siendo menor la población de paraguayos, brasileños y argentinos. Tal proceso inmigratorio dio lugar a una configuración étnica que no encuentra al llegar, 
de acuerdo con Bartolomé (1982), una matriz cultural "argentina" que pudiera asimilarla. Estas políticas dieron lugar al poblamiento de grandes zonas de la provincia, por parte de europeos, especialmente del este.

Contrariamente a ciertas posturas que consideraron a la producción teórica y las practicas aplicadas en campo como dos corpus diferenciales, el diseño de proyectos de intervención expresa muy fuertemente las concepciones teóricas que los investigadores portan?

\section{POLÍTICAS PÚBLICAS PARA POBLA- CIÓN INDÍGENA EN MISIONES}

La presencia indígena en la provincia de Misiones tardó en ser relevante tanto para las políticas públicas como para los medios masivos de comunicación. En los años previos a 1976, solo se destaca la "paupérrima" condición de vida, por ejemplo en una nota referida a los aborígenes de colonia Lanusse. Se destaca que no producen de forma intensiva, un tanto por no estar habituados y otro porque las maquinarias con que cuentan no pueden ser utilizadas en esa zona por ser un terreno muy pedregoso. Esta circunstancia los lleva a "subsistir de lo poco que ofrece la naturaleza circundante larvas, insectos, mamíferos, frutas, peces" y sigue (El Territorio, 10/4/1970). Estas expresiones en los medios masivos enuncian el desconocimiento sobre las condiciones de vida y las formas de subsistencia que los mbyá y los chiripa ${ }^{10}$ (eventualmente en menor proporción) habían utilizado ancestralmente.
Esta "pauperrima" modalidad de subsistencia ha sido registrada desde las primeras etnografías sobre el grupo y, podríamos considerar que representa la forma de subsistencia de los pueblos de esta zona (Susnik 1983).

Los medios masivos adelantan la necesidad, que luego expresarían las políticas, de convertir a las comunidades en grupos productivos, ya sea mediante la implementación de los programas de desarrollo en sus propias tierras o vendiendo su fuerza de trabajo en fincas. Es importante considerar que a principios de 1970 las tierras cultivadas de la provincia era muy pocas, permitiendo el uso del monte como medio de subsistencia.

Durante el proceso de colonización (desde 1897 a 1937 aprox.) se crearon 85 colonias en la provincia (38 oficiales y 47 privadas). La colonización de tipo oficial ${ }^{11}$ tuvo lugar principalmente en la zona Centro-Sur. En la mayoría de los casos, los inmigrantes se asentaron de acuerdo a sus orígenes étnicos y nacionales (formando grupos de descendientes de polacos, ucranianos, escandinavos, alemanes, y suizos). Pero la década de 1970 inaugura cambios de gran importancia para la provincia (al ritmo de los cambios de la política y la economía nacional), no sólo en materia de población indígena. Un emblema de esos cambios es, en 1978, la apertura de Alto Paraná. Este dato abre el camino para las transformaciones mas salientes de la economía local, que ahora se caracterizaría por la desregulación en la producción (que para el caso de la yerba mate produjo una rápida concentración de su producción) y, por un 
cambió del perfil productivo, dejando de lado la actividad agropecuaria e impulsando los negocios forestales ${ }^{12}$.

Según documentos oficiales ${ }^{13}$, la estructura productiva de la provincia se asienta fundamentalmente en la "industrialización de los productos primarios provinciales, tales como los aserraderos, la industria celulósica-papelera, la preparación de yerba mate, tabaco y té". Dentro de estas actividades la explotación forestal es la principal, ya que se nutre tanto de especies que se siembran, también aprovecha maderas duras extraídas de otras zonas. Las maderas mas valiosas son las especies propias del bosque nativo. Este tipo de madera se extrae de los espacios que todavía quedan de selva paranaense; en muchos de esos sitios viven comunidades indígenas. Estas variedades no se replantan y por tanto el resto de las especies (animales y vegetales) que se asociaban a estas se pierden también ${ }^{14}$. El medioambiente se deteriora porque el sol llega con más fuerza a las capas exteriores de la tierra, generando mayor recalentamiento. Los árboles añosos suelen cubrir a los ejemplares que dan frutos de importancia para la dieta mbyá.

De algún modo aquí se define una categoría de desarrollo, que tuvo su impacto en las propuestas de política indígena. El "Proyecto de desarrollo integral de las comunidades guaraníes de Fracrán y Peruti” se proponía explícitamente "incentivar la máximo el deseo de progreso, participación y toma de decisión por parte de la comunidad en todo lo que respecta a los subprogramas"15. Quedar por fuera de los mismos, suponía atraso y del mismo modo participar sin la sistematicidad necesaria para que sean proyectos de lucro, esto se plasma en la evaluación de una docente quien respecto de los frutales sostiene que "se observa sobreproducción por falta de adecuada comercialización"16.

El mismo proyecto sostenía como necesaria la "aculturación planificada, controlada, que se plantea como sistemática y que apunta a largo plazo" (Amable y Dohmann 2003: 5). En tal sentido la impulsora del proyecto sostiene "Esta fue dictada por las mismas sociedades descolonizadas que no querían perder las ventajas de la civilización occidental; fueron ellas mismas las que pidieran ayuda a las naciones occidentales para el aprendizaje de la tecnología moderna. Pero el pedido implicaba que tal aculturación material fuese manejada por los sujetos mismos (...) bajo el modo de una evolución interna, de un desarrollo coherente, y no de una revolución negativa y destructora de sus valores fundamentales" (Amable y Dohmann 2003: 5)

Al ver al trasluz estas experiencias, no solo a través de los dichos de sus mentores, sino cuando los sujetos a través de la práctica en años han logrado seleccionar, aprobar y rechazar a su modo aspectos de esta acción, nos llevan a plantearnos la influencia de nuestros propios prejuicios, valoraciones, intereses, etc. en el proceso de investigación y particularmente en las acciones. En referencia a ello, Peter Fry (1984) en su análisis de la obra de Roger Bastide señala cómo las valoracio- 
nes ya positivas, ya negativas de ciertas prácticas religiosas o en otro sentido, no solo pueden constituirse en prejuicios sino también consolidar campos de investigación "legítimos" e "ilegítimos" en función de intereses y valoraciones subjetivas (Spadafora 2005).

Estos emprendimientos ligaban directamente al gobierno provincial y eventualmente nacional, con quienes los diseñaban. Por un lado, porque eran contextos políticos donde pensar, pero fundamentalmente poner en acto, un programa podía poner en riesgo la integridad. Por otro lado, porque era el estado nacional quien financiaba estas políticas. Las fotografías de los primeros tiempos de Peruti muestran en la inauguración de las instalaciones las fotografías militares. De hecho, en la actualidad, las escuelas, que permanecen en funcionamiento lo hacen como "privadas", o mejor dicho con gestión privada y subsidio estatal completo.

En la provincia de Misiones, las políticas educativas focalizadas en relación a la cuestión indígena tardaron en hacerse presentes. Hubo algunas aproximaciones durante la década del noventa, y finalmente el desarrollo de un proyecto de Educación Intercultural Bilingüe a partir de 2005 (Enriz 2009, Arce et al 2007).

El proyecto de modernización de la etapa 1976-1983 se plantea "garantizar y asegurar la subsistencia de los aborígenes, promocionar el apoyo y cooperación para que logren su desarrollo por si, (...) y promover la actividad artesanal" (Acción de gobierno 19761983). Descontando que parten de considerar que la situación en que se encuentran dista de desarrollo, proponen instalar comedores, o en el mejor de los casos aportar técnicos para producir huertas. La sedentarización y la obtención de alimentos a través de las políticas de estado tienen como contrapartida la "liberación" del monte, es decir, el confinamiento a zonas muy reducidas. Por un lado las políticas tienden a familiarizar a la población con esas dinámicas productivas. Por otro lado, truncan la forma de subsistencia que se venía utilizando. "El objetivo final del este proceso será que logren afirmar cierto dominio sobre la naturaleza y por lo tanto independencia con respecto a ella" ${ }^{17}$, lo que permitiría producir en términos capitalistas.

Los beneficiarios de estos proyectos, es decir, los Mbyá-Guaraní de entonces en Misiones aparecían caracterizados como representantes de un modo antiguo de vivir, arcaico, que debe ser superado, en una definición que claramente omite la voz de los otros muy a pesar de que pregona "seis años de amistad, confianza, conocimiento mutuo e intercambio extremadamente respetuoso entre dos partes" (Amable y Dohmann 2003: 6).

En relación a la voz de los mbyá a la hora de que estos proyectos fueran llevados a cabo es importante considerar que para el Obispado de Posadas ${ }^{18}$ "fueron los aborígenes los que pidieron al Señor Obispo que les proporcionar los medios necesarios para que sus hijos pudieran entrar en la sociedad argentina a partir de lo que ellos son", nos interesa en este sentido comprender que se entendía por lo que los Mbyá 
son, en estos proyectos. ¿Son sujetos que necesitan ingresar a la economía de mercado? ¿Son quienes no pueden asegurar su subsistencia? ¿Qué extingue primero el desinterés o la intervención obtusa? ${ }^{19}$

¿Qué conocimientos sobre estas poblaciones se encontraban disponibles para la población general? A principios de la década del '70, aparecieron en la opinión pública una serie de noticias respecto de un censo indígena realizado en la provincia recientemente ${ }^{20}$. La noticia deja constancia de la dificultad que representó la recolección de datos "mujeres que no vacilaron en internarse en la selva solas, para cumplir con el cometido" (El Territorio, 5/8/1969). A esto se suma que "los indígenas no se encontraban inscriptos en ningún Registro de las Personas" (op. cit.), lo que fue resuelto mediante la recolección de los nombres de cada persona - y no de la cantidad de personas que era el plan inicial -, además de esto se recogió información sobre las condiciones de vida, la que es descripta de la siguiente forma: "se precisó que los indígenas pertenecen a la raza guaraní, sin acusar mayor evolución en relación a su grado cultural anterior" (op. cit.). De este modo comienzan a aparecer referencias al mundo indígena en los canales de circulación de información.

El subtitulo donde se expresan los resultados se enuncia: "Los indígenas que aún quedan", y en el mismo se habla de su "pobre existencia", se dice de los mismos que viven nucleados en parcialidades, con sus autoridades, subsisten de la agricultura de productos regio- nales: mandioca, batata, zapallo, maíz, maní, porotos, etc. "para cuyo efecto siguen utilizando el viracua", palo punzante con el que hacen el hoyo donde se coloca la semilla o el tallo para la futura planta. Cuando la zona lo permiten realizan también pesca, caza, recolección de frutos del monte "actividad que día a día se restringe mas en razón del avance de la población y las exigencias del progreso regional" (op. cit.). Lo que se expresa también es que la población esta migrando, se habla de "éxodo" causado por el desentendimiento o incomprensión del resto de la población. Pero posiblemente el éxodo sea hacia la provincia de Misiones, y lo estimules los avances sobre los montes centralmente el Brasil, pionero en la materia.

Por un lado en que visibiliza la presencia aborigen, y al mismo tiempo preanuncia las políticas de gobierno, dando lugar a pensar la necesidad de que sean "legalizados", como luego pretendería el decreto sobre el que se habló en las primeras líneas de este trabajo. Así como que se desarrollen, como fundamentaremos en las próximas líneas.

Se expresa la inevitabilidad de que abandonen el monte y vivan en los pueblos, "se verá obligado a abandonar su hábitat porque el progreso es cruel y el banco es el enemigo natural de lo autóctono, desde el indio hasta el pez" (El territorio, 14/8/1970) ${ }^{21}$. Para paliar este riesgo se propone la implementación de reservas, es decir, generar espacios pensados especialmente para la aculturación programática. El proyecto argumentaba la necesidad de dar respuesta a un pedido de "ayuda" 
que las mismas comunidades realizaran y declamaba buenas intenciones: "fueron ellas mismas las que pidieron ayuda a las naciones occidentales para el aprendizaje de la tecnología moderna. Pero el pedido implicaba que tal aculturación material fuese manejada por los sujetos mismos, de acuerdo a su manera de pensar, sentir, o sea de los modelos proporcionados por su patrimonio cultural" (Micolis en Amable y Dohmann 2003: 5).

Coincidimos con Spadafora que "este juego entre la familiaridad y el exotismo, la cercanía y la distancia, en el que se despliega la labor etnográfica, nos obliga a pensar críticamente en torno al proceso de traducción entendido no ya como un espacio neutro de producción del conocimiento, sino fundamentalmente como un "campo de negociación” (Conklin y Graham 1995). Esta perspectiva, lejos de desarticular la práctica etnográfica y su importancia en la producción de conocimiento, permite contextualizar política e ideológicamente nuestra labor al tiempo de entender el encuentro etnográfico como un espacio mutuamente construido cuya explicación, si bien no se agota en la retórica de la dominación y la resistencia, actualiza relaciones asimétricas de larga data" (Spadafora 2005: 149).

\section{REFLEXIONES SOBRE LA INTERVEN- CIÓN EDUCATIVA}

Innegablemente el pensamiento como tal y las ciencias sociales como parte de los desarrollos del pensamiento se encuentran influidos por las diversas corrientes teóricas en boga en cada período y fundamentalmente por los procesos histórico-políticos de que forman parte.

Las políticas de intervención de 1978/1984 se enmarcan en un período que ha significado una divisoria de aguas en Argentina. Las perspectivas hegemónicas sobre la diferencia construyeron como necesaria la igualación a cualquier precio como política gubernamental.

A simple vista se ven muy claras las transformaciones que el proyecto se propone, pero la forma en que estos cambios se instalan parece descontextualizada. Tanto los programas habitacionales, los productivos y los educativos se enfrentaron a grandes conflictos, el primero de los cuáles ha sido el desconocimiento.

De los emprendimientos propuestos, dos décadas más tarde - cuando comencé mi trabajo de campo - solo permanece en pie la escuela. En definitiva, la verdad estaba expresada desde el principio, cuando se fundamenta la intervención en las comunidades, los mentores del proyecto, citan al Paĩ Antonio Martínez, el más relevante líder religioso de la región en aquella época, quien solicitara escuela para sus comunidades; "las palabras de Paĩ Antonio reforzaron mi convencimiento de que debíamos ocuparnos de la atención de los aborígenes de las provincia en forma sistemática e integral" ${ }^{\prime 22}$.

El desconocimiento o la falta de herramientas necesarias generaron una escuela bilingüe donde la lengua indígena estaba ausente. Se convocaron docen- 
tes del Paraguay a educar, no solo en el ámbito escolar, sino también a permanecer en la comunidad "en este aspecto tan delicado y donde la interacción de aborígenes y no aborígenes debe estar guiada por la comprensión que nace de la generosidad, la confianza y la clarividencia que es siempre cauta, la perspectiva general será necesariamente la del bilingüismo y del biculturalismo, sin embargo siempre a partir de la lengua y la cultura guaraní" (Micolis en Amable y Dohmann 2003: 21). La educación bilingüe comenzó a proyectarse en una lengua que no era la mbyá. Además, esta diferencia no fue suficientemente registrada, no se crearon en aquel momento materiales que aportaran como escalón entre ambas variantes.

Del mismo modo funcionaron las experiencias en cuanto a la gradualidad de su implementación; fueron radicales. Los niños indígenas pasaron de no concurrir a ningún tipo de establecimiento educativo a formar parte de escuelas de doble jornada reforzadas por colonias de verano. Con docentes que, además, hablaban de otra forma el guaraní y se proponían introducirlos en el español.

Coincidimos con Miguel Bartolomé en la importancia que la etnografía como tal tiene a la hora de dar lugar a ámbitos de intervención, de diseños de políticas: "la conquista espiritual y económica continúa. Sin embargo, las culturas indígenas se están rediseñando pero no desapareciendo, como lo pronosticaban algunas ópticas basadas en la percepción exterior de las diferencias. A pesar de las múltiples compulsiones a las que han sido históricamente sometidos, y de las que continúan siendo objeto en el presente, los distintos rostros indígenas han sobrevivido a las agresiones y están ingresando al tercer milenio de una cronología que les era ajena, pero a la cual ahora están definitivamente ligados" (Bartolomé 2004: 200). Tanto hubiera aportado una reflexión sistemática a partir de una etnografía, a quienes diseñaron estas propuestas.

Para el caso particular de estos proyectos, se destaca la aplicación de políticas muy poco consensuadas, como grandes apuestas que llegan de una vez; con escasa capacidad de reformulación, con grandes respaldos de inversión y con objetivos de amplia intervención y modificación completa de la vida de los sujetos. Los docentes nombrados, que habitaban junto con algunos religiosos en viviendas junto a la población indígena, se encargaban de supervisar el funcionamiento de las propuestas productivas.

Por otro lado la política de 'reservas', de la que esta población parece haber formado parte, esta asociada a la protección diferencial. Hablamos de reserva, en tanto se consolidó un territorio donde los indígenas fueron convocados a habitar, cercano a una zona donde se afincaban. Ese territorio luego supuso estos niveles de transformación. Cómo símbolo, estas unidades territoriales de transformación fueron nominadas como "Aldeas", y esta denominación aún hoy puede leerse en diversos lugares - como por ejemplo el tanque de agua. 
Las políticas actuales asumen la presencia de los Mbyá como población permanente y no en extinción. En este sentido los Mbyá han aprendido a poner su voz y su conformidad/ disconformidad en asuntos de gobierno ${ }^{23}, y$ así las políticas públicas actuales requieren mayor consenso.

También han cambiado las instituciones asociadas. El lugar en las decisiones gubernamentales de la Iglesia católica se ha transformado, del mismo modo que el de las ONG. La primera no constituye actualmente un cuerpo monolítico de decisiones, sino que existe al interior de ésta diversos intentos de cómo vincularse con las comunidades. Distintas actitudes y perspectivas. Las segundas han ganado terreno y suelen gestionar su financiamiento, ya sea gubernamental, a través de financiadores externos o del aporte de particulares.

Si bien los comienzos de la escolaridad indígena en Misiones han estado asociados a las intensiones religiosas - ya que los primeros docentes dentro del ámbito público fueron también religiosas -, las modalidades de intervención en la vida social han sido muy diversas. Mientras en los primeros casos se instalaba la escolaridad como parte de una intervención mayor, en el otro la escuela era el único elemento, y el rol docente podía circunscribirse al trabajo en el aula.

Respecto de lo educativo, las políticas públicas actuales han demostrado que la participación activa de diversos miembros del grupo, en la producción y en la ejecución de las propuestas educativas es un elemento necesario a la hora de abordar problemáticas com- plejas. Así, la participación de indígenas en la capacitación, en la producción de materiales y en la coordinación de las clases junto con docentes y niños, ha permitido un aumento en el interés por la escolarización. El involucramiento se ha visto directamente ligado a la dinamización de la presencia adulta en el ámbito escolar en diversos lugares.

\section{A MODO DE CIERRE}

Las políticas de gobierno implementadas durante última dictadura militar en Argentina, por un lado visibilizaron a ésta población, tanto a través de los medios, como de la política de gobierno. Pero, por otro lado, la inventaron a su medida para ser plausible de las políticas focalizadas. En un mismo juego ha sido visibilizada para ser ocultada, a través de proyectos homogeneizadores que no consideraron las particularidades.

Coincidimos con Lins Ribeiro (1987) en que los proyectos a gran escala "se nutren de las desigualdades económicas existentes en niveles nacionales e internacionales, y de la asunción acrítica de concepciones que estimulan la creencia de que, para un futuro viable, cuanto más grande mejor" ${ }^{24}$. Del mismo modo el ingreso de proyectos de intervención supone una acceso a través del cual luego cruzarán otros emprendimientos.

Como lo considera Ana María Gorosito Kramer, "el indio es materia prima de un proceso de transformación que conduce a su redención por la vía del trabajo y del aprendizaje" (Gorosito Kramer: 1992: 6). Esta cosificación de los sujetos lleva a perderlos de vista, a 
olvidar sus particularidades en pos de su homogeneización en el plano "nacional". El respeto de la particularidad necesaria para un mundo intercultural, donde la diferencia ampliamente y retroalimente a los sujetos es, en gran medida todavía, parte de las deudas en torno a las poblaciones indígenas del país.

La presencia de adultos mbyá en el ámbito escolar es un elemento que refuerza la posibilidad de construir una escolaridad indígena que no sea producto de un sueño blanco, sino de los intereses y las modalidades compartidas.

\section{NOTAS}

${ }^{1}$ Para una reflexión particular sobre este tema ver: Arce, Hugo y Rita Allica, 2007. "Problematizando el trabajo del antropólogo en Educación Intercultural Bilingüe" Ponencia presentada en RAM VII, Poro Alegre, Brasil.

${ }^{2}$ Los auxiliares bilingües son, desde 2005, indígenas que forman parte de la escuela a partir de un programa de formación.

${ }^{3}$ Este trabajo comenzó a partir de ciertos interrogantes que se desarrollaron en el trabajo de campo del doctorado, en curso. No obstante, se sostiene en fuentes documentales de diverso tipo y en ciertas referencias a entrevistas.

${ }^{4}$ Con titulares del tipo "Los indígenas que aún quedan” El Territorio, 5/8/1969, Pág. 5 y 6.

${ }^{5}$ En el mismo desarrollamos trabajos de campo en diversas instancias entre 2005 y 2007.

${ }^{6}$ Ver mapa.

${ }^{7}$ En Argentina la escolarización se desarrolla a través de un doble sistema, pública o privada. La escolarización pública es laica, mixta y obligatoria. La privada, cuenta generalmente con subsidios del estado, que en ocasiones llegan al 100\% de los gastos.

${ }^{8}$ Para ampliar: Amable, María Angélica y Dohmann Karina. 2003. La educación bilingüe de los guaraníes den Misiones: La experiencia de Fracrán y Perutí. Instituto Superior "Antonio Ruiz de Montoya" Centro de Investigaciones Históricas "Guillermo Furlong".

${ }^{9}$ Para ampliar esta discusión ver: Hecht, Ana Carolina. 2007. De la investigación sobre a la investigación con. Reflexiones sobre el vínculo entre la producción de saberes y la intervención social. Runa No 27. En prensa.

${ }^{10}$ Los chiripá han habitado en muchísima menor proporción el territorio de Misiones, incluso en la actualidad sigue habiendo parte de esta población cohabitando con los mbyá.

${ }^{11}$ En el caso de la colonización oficial se hicieron entregas, en la mayoría de los casos, de parcelas de 25 has., y en algunos casos hasta 100 has., dependiendo esto del tamaño de la familia de los colonos. Respecto a la colonización privada, también el tamaño de las parcelas era de 25 a 50 has., y poseían un valor accesible. En ambos casos, el tamaño de la parcela estaba ligado al carácter que adquiere la producción en este sector: la explotación agrícola familiar.

${ }^{12}$ El último Censo Nacional Agropecuario confirma gran concentración: en la provincia existen 27.000 explotaciones agropecuarias. Sólo 161 de ellas (el 0,6 por ciento del total) poseen el 44 por ciento de la tierra de Misiones (917.000 hectáreas). El mismo estudio afirma que, en la última década y en la zona de Alto Paraná, descendió un 27\% la cantidad de pequeñas chacras. "Con su lógica de maximización del beneficio en el menor plazo posible, el sector forestal no respeta las normas de preservación, produce despoblación de las zonas y exterminio de gran parte de los recursos naturales", afirman desde el Foro de la Tierra. Ilustra- 
tivo es el caso de la Papelera Alto Paraná: es propietaria del diez por ciento del suelo provincial, 233 mil hectáreas. En el municipio de Puerto Piray, es dueña del 62,5 por ciento de la tierra.

${ }^{13}$ El boletín "Panorama Económico Provincial" que correspondiente a la Subsecretaría de relaciones con provincias de la Dirección Nacional de Programación Económica Regional. Septiembre de 2002.

${ }^{14}$ Así lo denunciaran las comunidades de la Reserva de biosfera Yaboti, entre otras.

${ }^{15}$ ISPARM, Archivo de Peruti y Fracran, Bibliorato Asuntos Varios, Autoevaluación de lo realizado entre agosto de 1979 y diciembre de 1980. En Amable y Dohmann, 2003: 26.

${ }^{16}$ Ibídem. Pág. 31.

${ }^{17}$ Ibídem. Pág. 19

18 "El intercambio y la promoción del autodesarrollo integral de las familias guaraníes. Fracran y Peruti: Misiones Argentina." Obispado de Posadas. Sin fecha.

${ }^{19}$ La documentación sobre el proyecto que elaboró la misma ISPARM no está disponible para el público en general. Y como dijimos, la información que existe en el archivo provincial es escasa.

${ }^{20}$ El mismo ha sido realizado por dos mujeres, Dora Ares de Parga representante de Instituto Indígena y R. Poujade de Kehoe, antropóloga misionera egresada de la Universidad de La Plata. Sus resultados se expresaron en "Mujeres que indicaron las condiciones de vida de los indígenas de Misiones” El Territorio, 5/8/1969, Pág. 5 y 6. "La extraña vida de los indios de Misiones" El Territorio, 10/4/1970 s/n .

21 "El extraño mundo de los indios guaraníes” El Territorio, 10/4/1970 Pág. 4.

22 Palabras de Monseñor Kemerer en:
Amable \& Dohmann, 2003.

${ }^{23}$ Enriz 2005.

${ }^{24} \mathrm{El}$ autor utiliza esta definición refiriéndose a emprendimientos de otras características absolutamente, no obstante, creemos que ilumina la reflexión sobre esta temática.

\section{REFERENCIAS}

Amable, M. A. y K. Dohmann. 2003. La educación bilingüe de los guaranies den Misiones: La experiencia de Fracrán y Perutí. Instituto Superior "Antonio Ruiz de Montoya". Centro de Investigaciones Históricas "Guillermo Furlong".

Arce, H., A. Benítez, E. Chamorro y M. Duarte. 2007. Rombopara Ore Ayvupy (Escribimos en nuestra lengua). Oralidad y Escritura Mbyá Guaraní. Trabajo presentado ante el VII Seminario de Lectura y Escritura en Sociedades Indígenas en el $16^{\circ}$ COLE (Congresso de Leitura do Brasil). UNICAMP, Campinas/SP, 10 al 13 de julio de 2007.

Bartolomé, L. 1982. Base social e ideológica de las ligas agraristas entre 1971-1975. Desarrollo económico 22(85).

Bartolomé, M. A. 2004. En defensa de la etnografía. El papel contemporáneo de la investigación intercultural. AVA Revista de Antropología 5. Universidad Nacional de Misiones.

Bastide, R. 1977. Antropología aplicada. Buenos Aires: Amorrurtu Editores.

Cadogan, L. 1971. Ywyra Ne'ery: Fluye Del Árbol La Palabra. Asunción: Ceaduc-Cepag. . 1948. Guahi Rataypy. Asunción: Ediciones Guarania.

1997 [1959]. Ayvu-Rapyta. Textos miticos de los Mbya-Guarani del Guairá. Asunción: Fundación León Cadogan, Ceaduc, Cepag. 
Enriz, N. 2005. Los paisanos en la plaza. Ponencia Presentada en las III Jornadas del Instituto de Ciencias Antropológicas, F F y L. UBA.

2009. Educación Indígena en Misiones. Ponencia Presentada en las XXVII Jornadas de Jóvenes Investigadores de la Asociación de Universidades del Grupo Montevideo. Entre Ríos, 26 al 29 de Octubre de 2009.

Garlet, I. J. y V. Assis. 2009. Desterritorialização e reterritorialização: a compreensão do território e da mobilidade mbyá-guarani através das fontes históricas. Fronteiras 11(19): 15-46.

Gordillo, G. y J. M. Leguizamón. 2002. El río y la frontera. Buenos Aires: Editorial Biblos.

Gorosito Kramer, A. M. 1992. Identidad étnica y manipulación, en Etnicidad e identidad. Compilado por C. Hidalgo y L. Tamagno. Buenos Aires: Centro Editor de América Latina.

Lins Ribeiro, G. 1987. “¿Cuanto más grande mejor? Proyectos de gran escala: una forma de producción vinculada a la expansión de sistemas económicos". Desarrollo económico 27(105): 4-27.

Malinowsky, B. 1991 [1926]. Crimen y costumbre en la sociedad salvaje. Barcelona: Editorial Ariel.

Perazzi, P. 2003. Hermenéutica de la barbarie. Una bistoria de la antropología en Buenos Aires, 1935-1966. Colección Tesis de Licenciatura. Buenos Aires: Sociedad Argentina de Antropología.

Sapadafora, A. M. 2005. La Circularidad de la Experiencia de Campo: poder y desigualdad en la producción del conocimiento. Campos Revista de Antropologia Social 4:135-154.

Susnik, B. 1983. Los aborígenes del Paraguay V. Ciclo Vital Y Estructura Social. Museo Etnográfico Andrés Barbero.
Fuentes:

www.helpargentina.org (Junio 2006)

http://www.isparm.edu.ar/bibliotecavirtual/catalogo/data/M/Mons_Kemerer_ SuCompromiso.htm (Julio 2006).

Recebido em 25/01/2010.

Aprovado em 28/02/2010. 